\title{
Seismic behaviour and strengthening of a vulnerable structure
}

\author{
F. V. Karantoni \\ University of Patras, Department of Civil Engineering, Greece
}

\begin{abstract}
The strengthening measures of an unusual masonry building of high seismic vulnerability are presented and assessment of their effectiveness is performed. The building is highly asymmetric and it is located in a zone of seismicity II, according to Greek Seismic Code. In addition, two adjacent walls have openings along $71 \%$ of their length. The building is scheduled and the authorities responsible for the preservation did not allow interventions that may alter its faces. Herein, the seismic response of the structure as well as the effectiveness of the finally adopted measures is presented. The effectiveness is assessed by comparing the overstressed areas of the original building with those of the strengthened one. The measures proposed are the replacement of flexible floors by stiff composite slabs, the construction of a reinforced concrete tie belt at the top of all structural walls, grouting of cement grout, repointing the masonry and the construction of a double shotcrete jacket.

Key words: masonry buildings, damage, vulnerability, strengthening.
\end{abstract}

\section{Introduction}

A historic or a scheduled building often remains undamaged regardless of the seismicity of the area, the empirical way of construction, and the lack of design. Sometimes, observing an old building makes us think that nowadays it would be constructed with a quite different engineering design. This paper is involved with such a building. The unusual structure under consideration is a building highly asymmetric in plane and in elevation, with few structural walls. The relatively high structural walls (up to $11.2 \mathrm{~m}$ ) of the north and west sides have many openings of approximately $71 \%$ of the length of the walls, the upper storey has an area of about one half of the lower storey, and the building has no rigid diaphragms. It has floors and a roof of timber joists. 
The rehabilitation of the building, which will be used as a school for adults, imposed the assessment of the structure under the seismic forces specified by the current policy. According to the specifications of the Greek Aseismic Code, the verification of existing buildings has to be done with the seismic loads as applied to new structures. From the first visual inspection of the structure, one can conclude that the fulfilment of the regulations in force is extremely difficult without drastic measures. In addition, there were two factors that prevented taking such drastic measures. These factors are: (a) the building is a scheduled one and consequently several restrictions arise, because the interventions must not alter the external appearance of the building, and (b) the existence of a system of cross vaults in the inner of the building, which constitute the roof of the basement, $50 \mathrm{~mm}$ apart from the load bearing walls prevent the erection of any load bearing element inside the building. This paper focuses on overcoming these difficulties.

\section{Description of the building}

The building was erected around 1900 AD. The data collected shows that it was built in two phases. One part of the building has three storeys with a total height of $11.2 \mathrm{~m}$, and the other part has two storeys with a total height of $7.0 \mathrm{~m}$. The adjacent wall (running from east to west) carries the load from the two parts. Each one of the two sections has a basement. In Fig. 1 the plane view of the storeys is presented. The main material of the structural walls is uncoarsed stone masonry but some parts are of solid bricks and some other of parallel alternate rows of solid bricks and stone. The building has floors of wooden beams and a roof of wooden truss and clay tiles and its main characteristic is the high percentage of openings in the north and the west side $(71 \%$ of the length of the walls, see Figs. 1 and 2), and the two cross vaults which constitute the basement roof (see Fig. 3). One of the four columns, which support each one of the cross vaults, is also shown in Fig. 3. These columns are not in conjunction to the structural walls but they are $50 \mathrm{~mm}$ apart. The openings in the south face have been filled up with stone and cement blocks. The openings in the west side of the second storey of the two storey part of the building have also been filled up. These walls are embedded to the adjacent walls and are not jointed to them. This yields the separation of the majority of the vertical interfaces due to developed cracking. On the ground floor the only internal wall running from north to south is supported from the vaulted roof of the basement and was added after the erection of the building. This wall has developed diagonal cracking near the lower part due to settlement. Another unusual characteristic is that the openings of the ground story intersect the floor of the first storey (see Fig. 4).

It is worth mentioning that the masonry has not developed seismic damage though the neighbourhood has been shaken by earthquakes during the life of the structure. The damage to the walls is caused by human interventions and by decay due to the lack of conservation and has led to a serious degradation of the masonry quality. The poor condition of the masonry and the high percentage of openings increase the seismic vulnerability of this structure; yet in spite of 
which, it has no seismic damage. The local authorities that are the owners of this building demolished the roof and the floors and subsequently they asked for a study to strengthen the building.

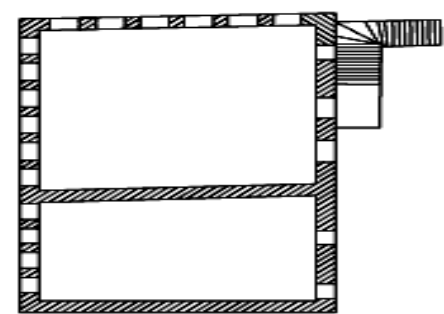

a)

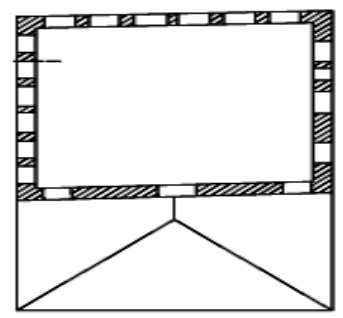

c)

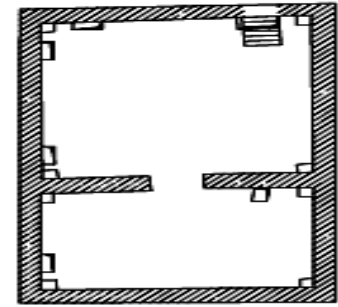

b)

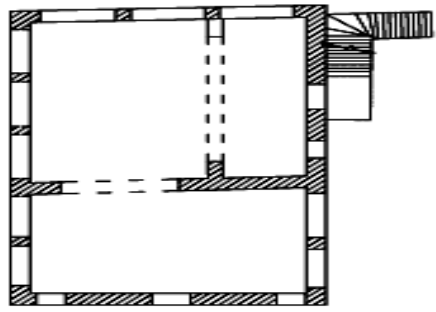

d)

Figure 1: Plane view of the building: (a) basement, (b) ground, (c) first, and d) second storey.

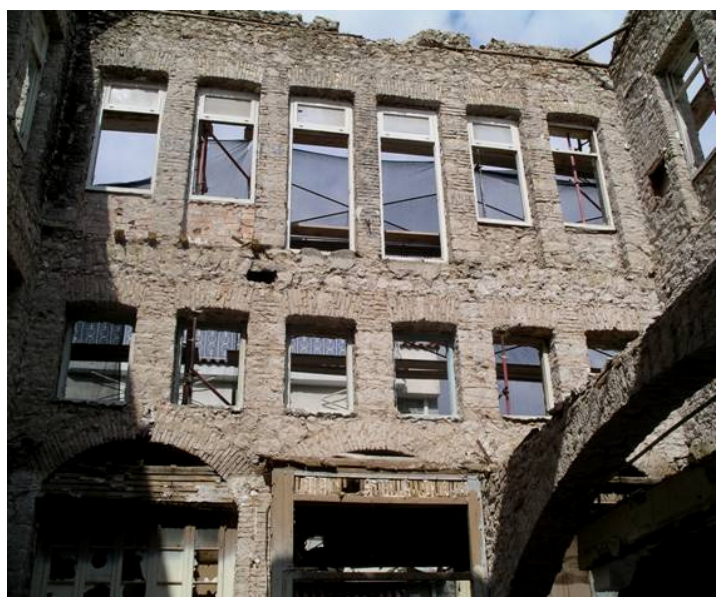

Figure 2: The inside north side of the building. 
336 Structures Under Shock and Impact X
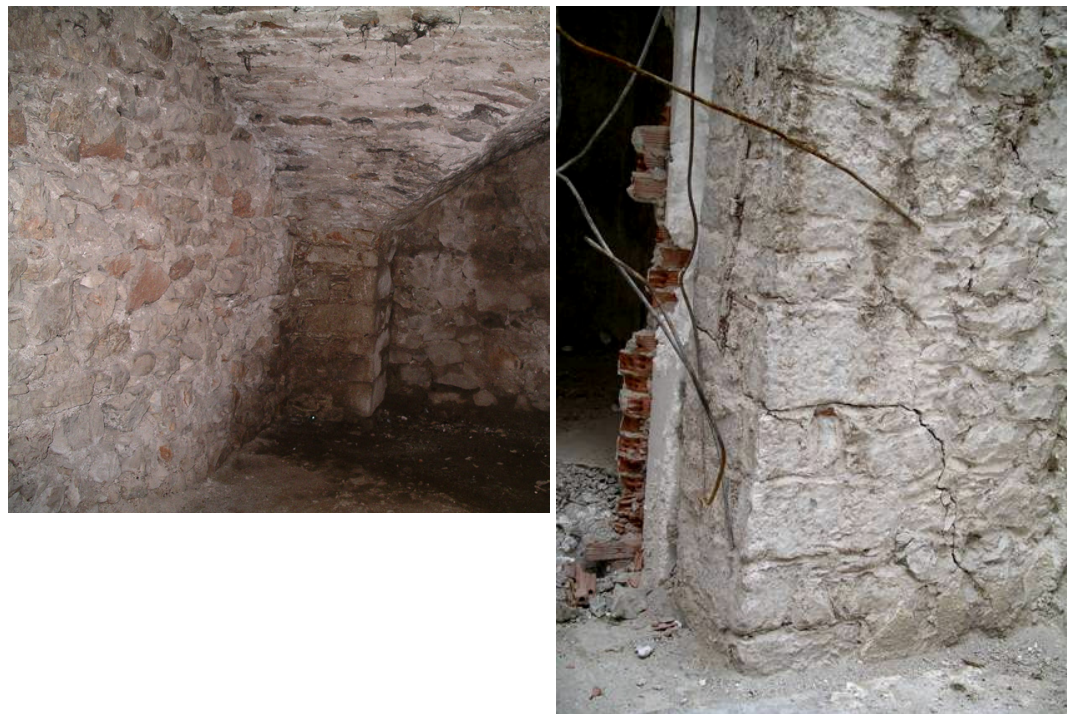

(a)

(b)

Figure 3: (a) The basement, and (b) the cracked arced wall of the ground floor.

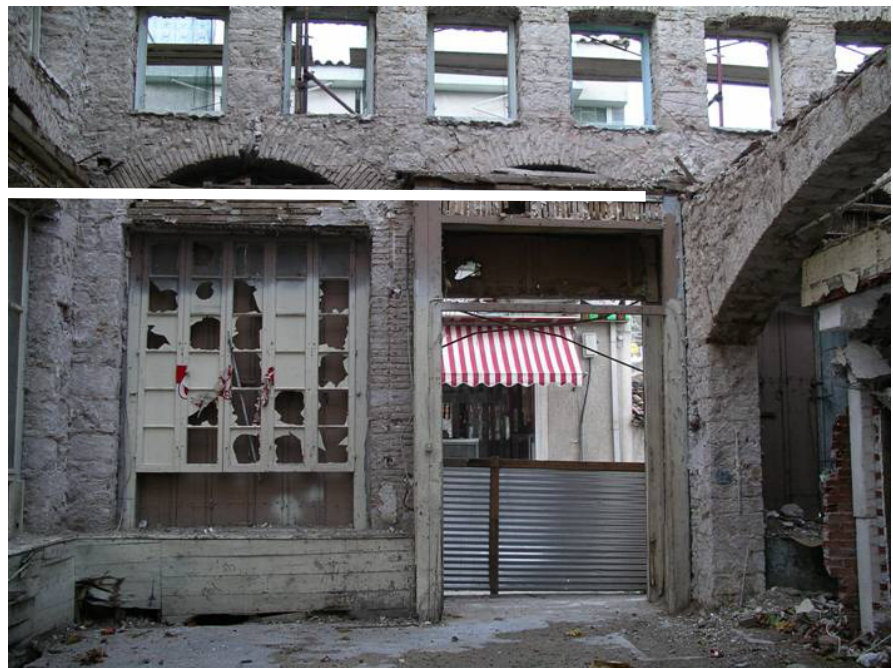

Figure 4: The inserted trace of the second storey floor, which intersects the arced openings. 


\section{Seismic verification of the existing building}

A preliminary analysis took place in order to propose strengthening techniques. The building without the floors and the roof was verified according to the codes in force. Then, a series of parametric analyses took place in order to adopt the most effective measures. In order to study the elastic dynamic response of the aforementioned building it was descritizated by a large number of triangular and quadrilateral finite elements (see Fig. 5), which are a combination of membrane and thick plate elements with 5 degrees of freedom per node, so they can undergo both in- and out-of plane motion. The Finite Element program ACORDCP [1] was employed for the analysis. A total of 5964 elements with 17020 degrees of freedom were used for the modelling of the structure. For the spectral analysis the design earthquake spectrum proposed by Greek Aseismic Code [3] was used for each one of the two horizontal directions, in conjunction with soil category $\mathrm{B}$, which represents the soil conditions under the structure.

The elastic modulus was obtained from the relation $E=1000 f_{w c}$, where $f_{w c}$ is the compressive strength of masonry. The parameter $f_{w c}$ was evaluated using the relation proposed by Tassios [7]:

$$
f_{w c}=\frac{2}{3} \sqrt{f_{b c}}-\alpha+\beta f_{m c} \quad \text { (in MPa) }
$$

where $\mathrm{f}_{\mathrm{bc}}$ is the compressive strength of the stones which are supposed to be 35.0 $\mathrm{MPa}$, while $\mathrm{f}_{\mathrm{mc}}$ is the compressive strength of the poor quality lime mortar that was taken equal to $1.0 \mathrm{MPa}, \alpha=2.0$ for uncoarsed stones and $\beta=0,5$ for stone masonry. The compressive strength was estimated to be $2.44 \mathrm{MPa}$.

First, a spectral analysis of the original building was performed. The equations (2) and (3) were used for the calculation of the spectral coordinate of the design spectrum shown in Fig. 6.

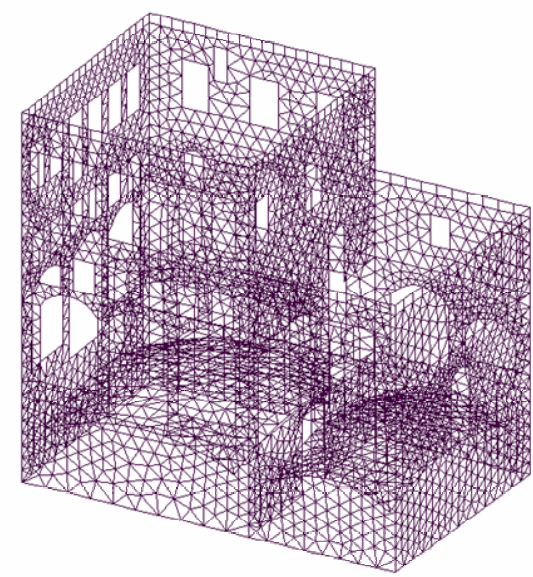

Figure 5: Finite element discritization of the building. 


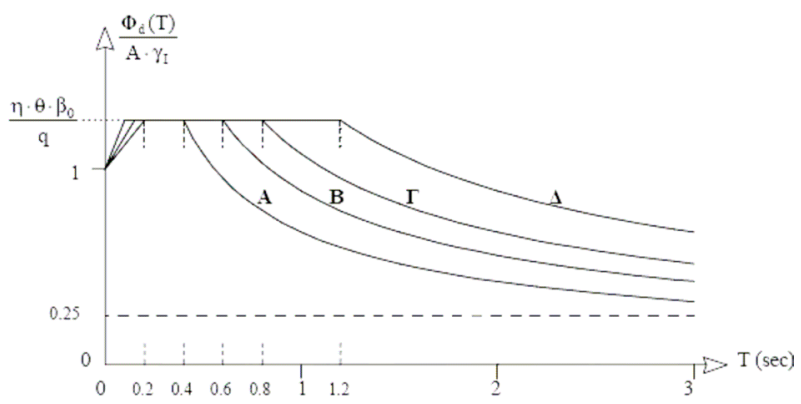

Figure 6: The design spectrum of Greek Seismic Code for $\frac{\eta \theta \beta_{0}}{q}=\frac{2.5}{2.0}$.

$$
\begin{aligned}
& \text { for } 0 \leq \mathrm{T}<\mathrm{T} 1 \\
& \text { for } \mathrm{T} 1 \leq \mathrm{T} \leq \mathrm{T} 2 \\
& \Phi_{\varepsilon}(\mathrm{T})=\gamma_{1} A\left[1+\frac{T}{T_{1}}\left(\eta \frac{\vartheta}{q} \beta_{0}-1\right)\right]
\end{aligned}
$$

Equation (2) corresponds to the increasing branch of the spectrum for $\mathrm{T}<\mathrm{T}_{1}$, where $T$ is the natural period of the structure and $T_{1}$ is the lower characteristic period for the soil category, here for soil $B$ with $T_{1}=0.15 \mathrm{sec}$. Equation (3) corresponds to the horizontal branch of the design spectrum and is valid for periods $T$ between $T_{1}$ and $T_{2}$, where the higher characteristic period $T_{2}$ for soil category $B$ is $0.60 \mathrm{sec}$.

The relations (2) and (3) employed with importance factor, $\gamma_{1}=1.15$, plain masonry structures with behaviour factor $\mathrm{q}=1.0$, damping correction factor $\eta=1.0$, with basement $(\theta=0.9)$, in Seismic Zone II $(A=0.24 \mathrm{~g})$, for $T_{1}=0.15 \mathrm{sec}$, and $\mathrm{T}_{2}=0.60 \mathrm{sec}$.

The modal shapes of the first significant mode of each direction are presented in Fig. 7. As is shown, the main characteristic of the modal shape in $\mathrm{x}$ direction (with natural period $\mathrm{T}_{\mathrm{x}}=0.43 \mathrm{sec}$ ) is the out-of-plane bending of the walls transverse to the $\mathrm{x}$ axis. The modal shape in $\mathrm{y}$ direction (with natural period $\mathrm{T}_{\mathrm{y}}=0.29 \mathrm{sec}$ ) is also the out-of-plane bending accompanied with rotation about the corner adjacent to the most stiff east and south walls.

The second phase was an equivalent static analysis with seismic acceleration $\mathrm{a}_{\mathrm{g}}=0.62 \mathrm{~g}$, which is obtained from Equation (3) for $\mathrm{T}=0.43 \mathrm{sec}$. Eight seismic combinations were examined: $\mathrm{G}+0.30 \mathrm{Q} \pm \mathrm{E}_{\mathrm{x}} \pm 0.3 \mathrm{E}_{\mathrm{y}}$ and $\mathrm{G}+0.30 \mathrm{Q} \pm 0.3 \mathrm{E}_{\mathrm{x}} \pm \mathrm{E}_{\mathrm{y}}$, where $G$ and $Q$ are the dead and live loads respectively, and $E_{x}$ and $E_{y}$ are the seismic loads along the $\mathrm{x}$ and $\mathrm{y}$ axes, respectively. The principal tensile stresses developed in masonry compared with the tensile strength of masonry, which was taken to be $0.10 \mathrm{f}_{\mathrm{wc}}$, namely $0.25 \mathrm{MPa}$. The analysis provides that under all seismic load combinations under consideration almost all the masonry is 
overstressed. In Fig. 8 the red (dark, in black and white mode) area represents the area of the walls where the principal tensile contours of inner face of the wall exceed the tensile strength of masonry. It is shown that only a small part of the building can sustain the design loads. The fact that the building remains without any seismic damage over one hundred years is due to the probabilistic determination of the design seismic loads. As is well known, the seismic loads are determined for an earthquake with repeat period of 475 years.

These discouraged results of the analysis in combination with the restrictions for the strengthening measures required the need of examining the effectiveness of various techniques [5-7]. Eleven new analyses were made for the assessment of various proposals. In the section that follows the most effective measure is presented.
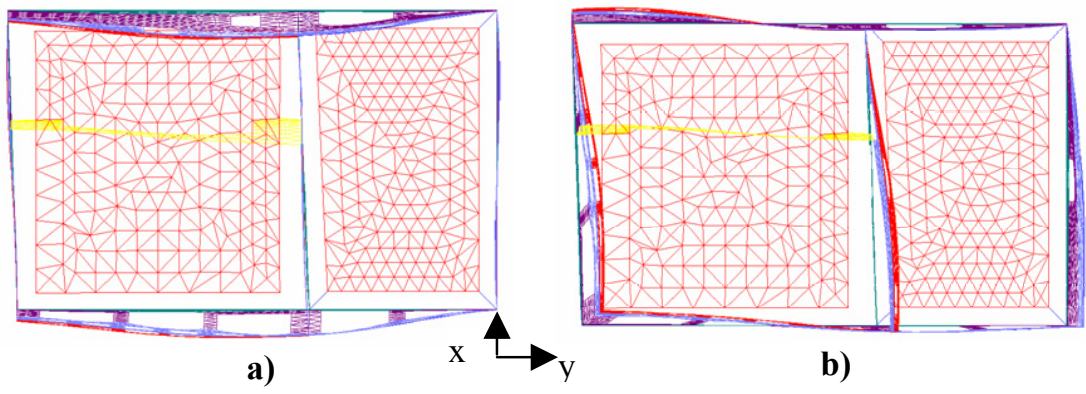

b)

Figure 7: The modal shapes of the original building along: (a) $x$, and (b) $y$ axes in plane view.

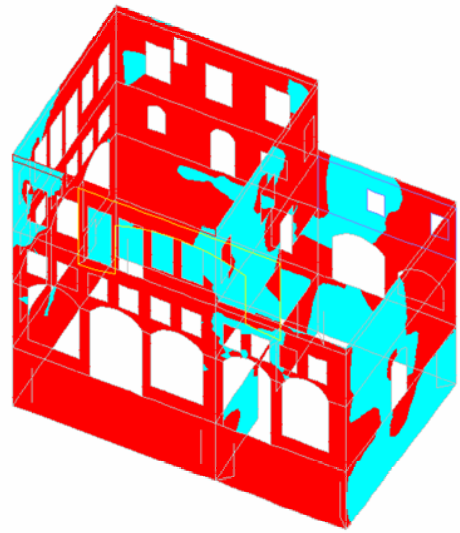

(a)

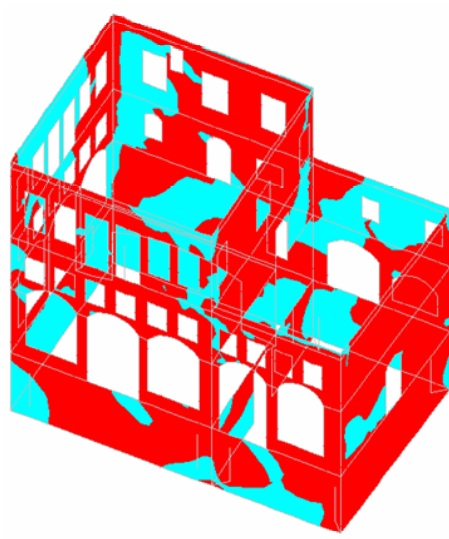

(b)

Figure 8: Contours of principal tensile stresses of the inner side of the masonry of the original building for: (a) load combination $\mathrm{G}+0.3 \mathrm{Q}-$ $\mathrm{E}_{\mathrm{x}}+0.3 \mathrm{E}_{\mathrm{y}}$, and (b) $\mathrm{G}+0.3 \mathrm{Q}-0.3 \mathrm{E}_{\mathrm{x}}-\mathrm{E}_{\mathrm{y}}$. The stresses of dark (red) areas exceed the tensile strength of the masonry. 


\section{Seismic verification of the strengthened building}

As mentioned in Section 3 the vulnerability of the building was originated from the morphology of the building and the interventions, which increased the asymmetry in plane view. Analyses proved that the alteration of these interventions (e.g. demolition of walls which closed the openings, demolition of the wall supported by the cross vaults, adjoining of the sills to piers) decreased only a little the stress state of the building. The need for extended interventions was imposed and the local authorities were convinced to accept them. Finally, the selected solution was the grouting with cement grout and repointing of the masonry, the replacement of flexible wooden floors by composite reinforced concrete slabs, the demolition of the wall supported by the vaults, the construction of a reinforced concrete tie beam at the top of the walls, and the construction of a double shotcrete jacket in all the structural walls. It is expected that the grouting and the repointing will increase the tensile strength of masonry more than $20 \%[2,8,9]$. Conservatively, the tensile strength of the masonry after these works was taken equal $0.30 \mathrm{MPa}$. Because of the limited space between the cross vaults and the walls, the thickness of the inside jacket was only $50 \mathrm{~mm}$. The thickness of the outside jacket is proposed to be 150 $\mathrm{mm}$.

A new spectral analysis was performed taking into account the modification of the structural system and the masonry properties. In Fig. 9 the modal shapes after the abovementioned strengthening techniques are shown. For excitation along the $\mathrm{x}$ axis, the walls of the three-storey section rotate about its south-east corner indicated by the letter A in Fig. 9 and the walls of the two-storey section rotate about the corner indicated by the letter B in Fig. 9. For excitation about the $\mathrm{y}$ axis, a translation of all the walls along to the axis is observed. The natural periods of the modified building are found to be $T_{x}=0.14 \mathrm{sec}$ and $T_{y}=0.11 \mathrm{sec}$. Given that $\mathrm{T}<\mathrm{T}_{1}$, the calculation of the seismic load is obtained using Equation (2) with $q=1.5$ for the strengthened building, which gave a spectral acceleration $0.413 \mathrm{~g}$. The measures result in a dramatic reduction of the principal tensile stresses on masonry as shown in Fig. 10. Indeed, only some elements at the springs of arced openings of the ground storey seem to be overstressed. Local prestressing on these areas may entirely solve the problem.

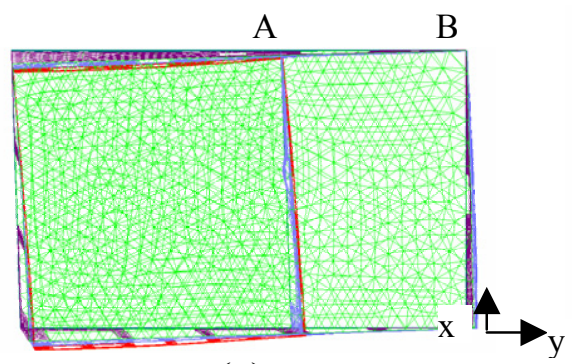

(a)

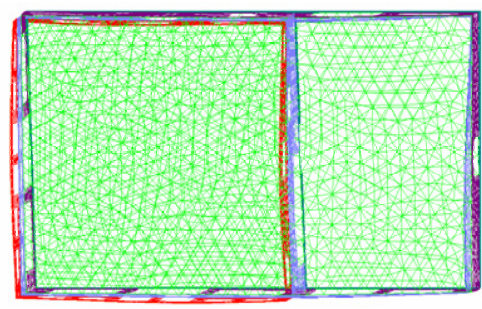

(b)

Figure 9: The modal shapes of the strengthened building along: (a) $\mathrm{x}$, and (b) $\mathrm{y}$ axes, in plane view. 


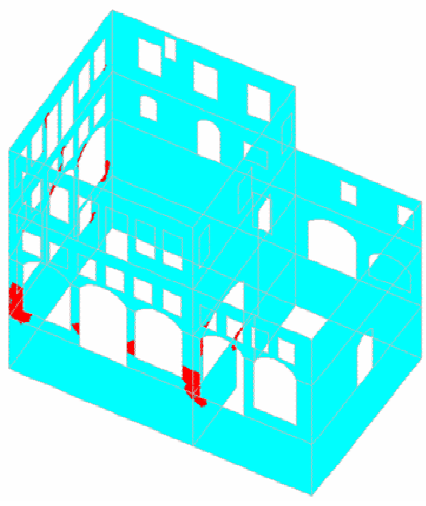

(a)

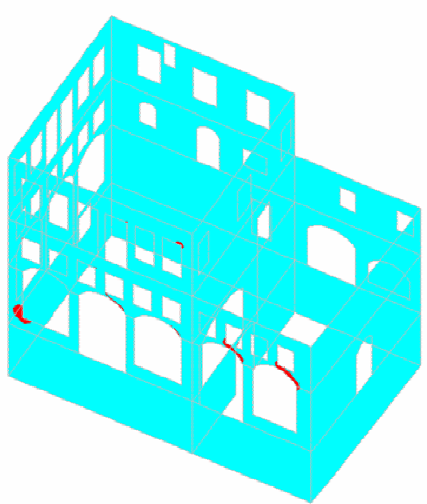

(b)

Figure 10: Contours of principal tensile stresses of the inner side of the masonry of the strengthened building for: (a) load combination $\mathrm{G}+0.3 \mathrm{Q}-\mathrm{E}_{\mathrm{x}}+0.3 \mathrm{E}_{\mathrm{y}}$, and (b) G+0.3Q-0.3 $\mathrm{E}_{\mathrm{x}}-\mathrm{E}_{\mathrm{y}}$. The stresses shown as dark (red) areas exceed the tensile strength of the masonry.

\section{Conclusions}

Very often it is difficult for the existing structures to fulfil the specifications of modern seismic codes and wide interventions have to be made. However, the proposed strengthening measures are declined by the preservation authorities in order to preserve the appearance of a structure. These conflicting concepts are challenging the engineers involved with the strengthening of traditional buildings. Sometimes, it is only the persistence to the ideas proposed by a specialist that may persuade the authorities to overcome their hesitation and adopt the proposed measures. In the unusual building under consideration, however, the interventions described in section 4 were suggested by the author from the beginning and the authorities demanded measures that do not affect the external faces of the building. However, this building does not have any elements that can be preserved. The piers, which are about $0.70 \mathrm{~m}$ in length, were not capable of being highly prestressed. So, the replacement of flexible floors by stiff slabs, and the construction of the double jacket were unavoidable, and in combination with cement grouting, repointing and the construction of a reinforced concrete tie beam at the top of the walls, made the structure strong enough and almost fulfilled the seismic code in force.

\section{References}

[1] Acord-CP, Calcul par éléments finis. www.itech-soft.com.

[2] Boineau A. "Reinforcement des maçonneries par injections de coulis" Vth Int. Congress on Deterioration, Lausanne, 1985 
[3] Greek Aseismic Code, Earthquake Planning and Protection Organization, Athens, 2000

[4] Karantoni F.V. and Fardis M.N., "Analytical Study of Strengthening Techniques for Earthquake Resistant Masonry Buildings", Proc. 9th Europ. Conf. on Earthq. Engrg., V. 7B, pp. 125-134, Moscow, Sept. 1990.

[5] Karantoni F.V. and Fardis M.N., "Assessment of Intervention Techniques for Seismic Strengthening of Masonry Buildings", in proc. of 1st International Congress on Restoration of the Architectural Heritage and Building, Canarias, July, 1992.

[6] Karantoni F.V, Fardis M.N. and Matraka D. "Comparative study of the seismic response of stone and brick masonry buildings" in Dynamics, Repairs \& Restoration, Eds C.A. Brebbia, B. Leftheris, 1995, pp 61-68

[7] Tassios Th., Cronopoulos M.P., "Aseismic Dimensioning of Interventions (Repairs/ Strengthenings) on Low-Strength Masonry Buildings", M. East and Mediterranean Regional Conf., Ankara, 1986.

[8] Toumbakari E-E., Dionys Van Gemert, "Lime - pozzolana -cement injection grouts for the repair and strengthening of three-leaf masonry structures", $4^{\text {th }}$ Int. Congress on the Conservation of Mediterranean Monuments, V 3. TCG, Rhodes, 1997, pp. 385-394.

[9] Vintzileou E., Tassios T.P. "Three-leaf stone masonry strengthened by injecting cement grouts", International Journal of Rock Mechanics and Mining Sciences and Geomechanics Abstracts, V32, N8, December 1995, pp. 397A-397A(1). 